\title{
Public perceptions of the tone and emotional impact of educational news coverage
}

Dr Kathryn Shine

Curtin University, Journalism department

Western Australia

ORCID ID: https://orcid.org/0000-0003-3160-0028

Email: K.Shine@exchange.curtin.edu.au

Dr Shane L. Rogers

Edith Cowan University, Psychology department

Western Australia

ORCCID ID: https://orcid.org/0000-0002-6869-3400

Email: shane.rogers@ecu.edu.au

\begin{abstract}
This study examines teacher $(n=268)$ and parent $(n=206)$ self-reported perceptions of educational news coverage, and how the coverage affects them. Overall, the participants reported a perception that news coverage of teachers, schools, the education system, and standardised testing was generally negative in tone. Participants reported typically feeling demoralised by negative stories and inspired by positive stories. A high importance was placed upon the public perception of education by participants. However, trust in the media reporting of educational issues was low. An exception to this general pattern of findings was that participants did not place as much importance upon the public perception of standardised testing and reported being less affected by negative or positive stories on that topic compared to the other educational aspects. This research is one of the few studies to investigate the potential emotional impact news coverage of education can have upon media consumers.
\end{abstract}

Key words: Education news; negative news; positive news; trust in news; impact of news; parents; teachers; schools

Conflicts of interest/Competing interests

The authors declare no conflicts of interest.

Authors' contributions

Study conceptualisation (SLR, KS), Data collection (SLR, KS), Data analysis and presentation (SLR), Writing (KS, SLR). 
News about K-12 schooling appears frequently in local, metropolitan and national media. Editors perceive education news to be of interest to the high numbers of news consumers who have school-aged children. This interest has seen education grow in "prestige and editorial importance to become one of the top three or four areas of news coverage" in recent decades, according to British researchers (Hargreaves et al. 2007, p.5). Although many people have direct contact with schools, they tend to rely on the news media to inform them about the education system more broadly (Mills and Keddie 2010).

Scholars have recognised the impact that news coverage of schooling, schools and teaching can have on public perceptions, and a small but growing body of research into education reporting has emerged in recent decades. The research has considered the reporting of a broad range of education-related topics from standardised testing to the portrayal of schoolteachers, and the consensus has been that news coverage of education is highly influential. It is said to shape public opinion about schools and teachers and to influence government educational policy (Blackmore \& Thorpe 2003; Blackmore \& Thomson 2004; Cohen 2010; Lingard \& Rawolle 2004; Mockler 2018; Snyder 2008; Thomas 2003; Thomson 2004). According to Stack (2006, p. 65) the news media play "a central role in determining the issues that are debated and ultimately how policymakers and the public interpret these issues". This is particularly significant when one considers that related research has pointed to a prevalence of negative reporting of education since the 1990s (Baroutsis 2016; Baroutsis \& Lingard 2017; Mockler 2013; 2018; Coe \& Kuttner 2018; Shine 2017). School systems are frequently described as under-performing (Berliner \& Biddle 1995; Thomas 2006; Wallace 1993) and schoolteachers are regularly blamed for declining standards (Goldstein 2011; Mockler 2019; Shine 2015; Thomas 2011).

Most of the research investigating the reporting of education has concentrated on news content. To date, very few studies have explored how news audiences perceive, and respond to, the reporting of educational issues. The limited research that has been undertaken has focused on schoolteachers and suggests that they are concerned about a perceived negative and critical focus of news coverage, and that this type of reporting can upset and affect them (Blackmore \& Thorpe 2003; Mackenzie 2007; Shine 2017). The impact of negative coverage is such that some teachers have named it as a factor in their decision to leave the teaching profession (Fetherston \& Lummis 2012; Moore 2019). In a recent study of over two thousand Australian teachers, Heffernan et al. (2019) reported that $71 \%$ did not feel that the Australian public appreciates teachers. Our study outlined here builds on the limited existing research by outlining the results of a survey of teachers $(n=268)$ and parents $(n=206)$ about their perceptions of, and attitudes towards, news coverage of education. It also considers the impact of the reporting of education on participants. As the people who took part were either parents or schoolteachers, comparisons about the two groups will be identified and explored.

\section{Education in the news}

Traditionally, education has received little attention in the news compared to dominant topics such as politics and sport. However, this began to change from the 1980s when education became a key political issue in developed countries around the world. As the coverage grew, the nature and tone of the reporting generally became more critical of both school systems and schoolteachers (Shine 2019). While individual teachers may be lauded for their devotion to students, teachers generally have been subject to a range of negative descriptions in news coverage including "incompetent" (MacMillan 2002, p. 30) "untrustworthy" and "intransigent" (Thomas, 2006, p. 218) and "low achievers" (Shine 2015, p. 509). Similarly, while it is not uncommon to hear about a school achieving great results against the odds, the overarching narrative in the news has tended to be that school systems are in crisis and are failing to deliver the desired educational outcomes (Hattam, Prosser \& Brady 2009; Macmillan 2002; Wallace 
2007). Such coverage has generally presented a negative image of the education system and teaching as a job (Shine \& O'Donoghue 2013).

The attention given to issues of quality and standards in education news has been noted by numerous researchers (Cohen, 2010, Thomas, 2006; Thomson \& Cook 2014). Coverage of this nature has increased in line with the adoption of standardised testing across many countries around the world. In Australia, such tests include the Program for the International Student Assessment (PISA) and the National Assessment Plan - Literacy and Numeracy (NAPLAN). Studies have shown that the reporting of test results tends to concentrate on areas of decline and unfavourable comparisons, rather than improvement (Shine 2015; Stack 2006). While stories about high-performing individual schools or students are covered, most of the reporting focuses on negative aspects of performance (Baroutsis and Lingard 2017).

\section{Public perceptions and reactions to news}

Research about public perceptions of education news is limited, but what is available suggests that news consumers have a clear sense of the dominant tone of education reporting. An interview study of 25 Australian schoolteachers' perceptions of news coverage found that 88 per cent of the teachers interviewed considered education reporting to be predominantly negative (Shine 2017). Furthermore, the coverage was deemed to be unfairly negative and not generally representative of what was happening in schools. More than half of the teachers described news coverage of education as inaccurate and/or unbalanced and many reported a distrust of the news media and journalists. Such views are not uncommon, according to the findings of larger studies. For example, the Reuters Institute Digital News Report 2019 surveyed 75,000 news consumers from 38 countries and found that almost 4 out of 10 participants considered the news to be too negative. The level of trust in news had decreased to 42 per cent and only about half the respondents ( 49 per cent) trusted the media they themselves use. Additionally, news avoidance had increased with the most common reason to avoid news being that it had a negative impact on mood (Newman, Fletcher, Kalogeropoulos \& Nielsen 2019).

Research has also indicated that the tone of news can produce emotional responses in the news consumer (de Hoog \& Verboon 2020; Baden et al. 2019; Johnston \& Davey 1997; Marin et al. 2012; McIntyre \& Gibson 2016; McIntyre \& Gyldensted 2018; McNaughtonCassill 2001; Newman et al. 2019; Szabo \& Hopkinson 2007; Wormwood et al. 2018). For example, in a recent psychological study of the effect of general news on emotions, de Hoog and Verboon (2020) had 63 American adults report their mood and news exposure five times per day for 10 days. They reported a small but statistically significant effect of negative news coverage on daily mood. In a similar study, Wormwood et al. (2018) explored how a group of 95 American adults responded to newspaper coverage over two weeks. The intention was to examine responses to a broad range of news that encompassed the mundane to more dramatic. The authors found an association between news coverage and mental health, concluding that those people exposed to news coverage with a more negative tone reported more depressive symptoms. Conversely, people who were exposed to news stories with a more positive tone reported fewer depressive symptoms. Other researchers have also found a positive impact of positive news, such as McIntyre and Gibson (2016) who experimentally manipulated the tone of news stories to demonstrate how positive news can lift the mood of the reader. While research has investigated the emotional impact of news in a broad sense, there is a lack of research specifically investigating the potential impact of educational news on relevant stakeholders (such as teachers and parents). 


\section{The present study}

In her interview study of Australian schoolteachers Shine (2017) found almost all the participants considered media reporting of education to be predominately negative. The present study extends upon that qualitative work by conducting a quantitative examination (via survey) of a larger sample size of teacher and parent views regarding the perceived general positive/negative tone of educational news media. The inclusion of parents meant that we could ascertain whether teachers were particularly sensitive to news reports about education or whether their perceptions were shared by another section of community, albeit one that also has a connection to schooling. We hypothesised that like Shine (2017) most participants would perceive education news to contain a generally negative tone. Additionally, we surveyed participants' perceptions of different aspects of education - the reporting of news about teachers, schools, the Australian education system, and NAPLAN testing. We surveyed views about Australia's National Assessment Plan - Literacy and Numeracy (NAPLAN) as NAPLAN testing has been controversial since inception about 10 years ago (Mockler 2015; Rogers, Barblett \& Robinson 2016, 2018; Rose, Low-Choy, Singh \& Vasco 2018; Thompson \& Cook 2014) and, as previously discussed, NAPLAN is regularly in the news (Mockler 2013, 2015; Shine 2015; Thompson \& Lasic 2011).

There is an established literature demonstrating that in general news media can impact mood in negative (de Hoog \& Verboon 2020; Baden et al. 2019; Johnston \& Davey 1997; Marin et al. 2012; McNaughton-Cassell 2001; Newman et al. 2019; Szabo \& Hopkinson 2007; Wormwood et al. 2018) and positive ways (Baden et al. 2019; McIntyre \& Gibson 2016). Therefore, we hypothesised that teachers and parents might report experiencing a negative reaction and positive reaction to negative and positive educational news, respectively. It has also been suggested that a contributing factor to the psychological impact of news is a person's perceptions regarding how important or relevant the news is to them (de Hoog \& Verboon 2020). Therefore, to help explain why we might find that some participants report a strong reaction to education news we also explored the extent that surveyed participants felt that the public perception of education was important. We hypothesized that since both teachers and parents have a personal investment in education that most would care about the public perception of education. This is also why in the present study we investigate perceptions across different aspects of education that differ in the extent of personal relevance (i.e., Teachers, Schools, The Education System, and NAPLAN). We were anticipating that teachers would be more impacted by news media that has a higher level of personal relevance to them (Teachers and Schools) compared to more system level aspects of education (The education system, and NAPLAN). We also asked our participants the extent that they have trust in news coverage. As per the recent Reuters report (Newman, Fletcher, Kalogeropoulos \& Nielsen, 2019), we hypothesised that trust in news reporting about education would be relatively low.

\section{Method}

Participants

Participants were recruited via posting an advertisement about the study on the Facebook research page of one of the authors (SR). The sample consists of 268 teachers $(M$ age $=42.54, S D$ age $=8.92 ; 87 \%$ female $)$ and 206 parents $(M$ age $=42.79, S D$ age $=6.48 ; 91 \%$ female). Included within the teacher sample are 11 school principals. For the parent sample all participants indicated that they have school-aged children (primary or secondary) at the time of the survey. At the time of responding, participants lived across the states and territories of Australia with most of the teacher sample coming from Queensland (30\%) and most of the parent sample coming from Western Australia (46\%), see Table 1. 
Table 1. Frequency statistics for the Australian state/territory of residence of participants.

\begin{tabular}{lll}
\hline & Teachers & Parents \\
\hline Australian Capital Territory & $1(0.4 \%)$ & $0(0 \%)$ \\
New South Wales & $57(21 \%)$ & $28(14 \%)$ \\
Northern Territory & $1(0.4 \%)$ & $0(0 \%)$ \\
Queensland & $80(30 \%)$ & $39(19 \%)$ \\
South Australia & $21(8 \%)$ & $9(4 \%)$ \\
Tasmania & $7(3 \%)$ & $4(2 \%)$ \\
Victoria & $51(19 \%)$ & $31(15 \%)$ \\
Western Australia & $45(17 \%)$ & $95(46 \%)$ \\
\hline
\end{tabular}

Note: Five (2\%) of the teacher sample did not respond to this question.

\section{Measures}

In this study we used an online questionnaire to assess participant perceptions about news media reporting of several aspects of education: teachers, schools, the education system, and NAPLAN. Below we describe the questions by sub-section.

Participant exposure to education news. To assess participant self-reported exposure to news with an educational focus we asked several questions. First, participants were asked "How often do you read (or listen to) news stories?" on a response scale: (1) Multiple times per day (2) About once a day (3) A few times per week (4) About once a week (5) A few times per month (6) About once a month (7) A few times per year (8) About once a year (9) Less than once a year. Participants were then asked "Approximately what proportion of the news articles you encounter are focused on education?" on a response scale: (1) $1 \%$ or less (2) $2 \%$ (3) $5 \%$ (4) $10 \%$ (5) $15 \%$ (6) $20 \%$ (7) $25 \%$ (8) $30 \%$ or greater.

Perceptions of positive/negative tone of educational media coverage. Participant general perception of the overall positive or negative tone of education media was assessed via the question "In general, I feel like the media coverage of is typically:" on a response scale: (1) Very negative (2) Somewhat negative (3) Neutral (4) Somewhat positive (5) Very positive. This item was repeated where the was for: teachers, schools, the education system, and NAPLAN.

Reactions to positive and negative educational media coverage. To assess participant negative reaction to negative media participants were asked the question "When I hear/read a NEGATIVE media story about , I find it to be DEMORALISING", and to assess positive reaction to positive media the question used was - "When I hear/read a POSITIVE media story about , I find it to be INSPIRING". For both questions the response scale used was: (1) Not at all (2) A little bit (3) Quite a bit (4) A lot. Both questions were repeated for teachers, schools, the education system, and NAPLAN. The terms demoralising and inspiring were chosen based on specific suggestions in the literature that educators can find negative educational news items demoralising (Mackenzie 2007), and positive items inspiring (Liu \& Tsao 2013).

Trust in the media coverage of education. The general level of trust in educational media was assessed via the question "When I hear/read a media story about I feel like I can trust what I am hearing/reading" on a response scale: (1) Not at all (2) A little bit (3) Quite a bit (4) A lot. This item was repeated for teachers, schools, the education system, and NAPLAN.

The perceived importance of the public perception of education. To assess how important the participants feel the perception of education is by the public we asked the question "How is/are perceived by the public is important to me". The response scale used was: (1) Not at all (2) A little bit (3) Quite a bit (4) A lot. This item repeated for teachers, schools, the education system, and NAPLAN. 


\section{Results}

To statistically examine differences within and across the teacher and parent groups for the survey questions used in our study we first ran a series of $4 \times 2$ mixed design factorial ANOVAs. Rated aspect was the repeated measures factor with four levels (i.e., Teachers, Schools, Education system, and NAPLAN), and participant group was the between group factor with two levels (i.e., Teachers, and parents). All the ANOVA main effects and interaction effects were found to be statistically significant $(p<.05)$. A single exception was the main effect for the question about finding positive news stories inspiring where the effect of participant group was non-significant. However, the interaction effect was still significant so like all other questions we conducted follow-up t-tests to look more closely at where specific differences occurred. Due to the number of t-tests ran per question (i.e., $16 \mathrm{t}$-tests), to contrast all sub-items within and across participant groups we applied a Bonferroni adjustment (i.e., $.05 / 16, p=.003)$ to the accepted significant $p$-value to be more conservative to avoid committing a Type 1 error (i.e., accepting a result as statistically meaningful when it may have just occurred do to chance because of so many tests being run) (Field, 2013). For the sake of parsimony, we provide all ANOVA and t-test results in full in tables as an online supplement rather than reporting all these statistics in-text. An exception to our overall reporting strategy occurs in the initial results sub-section below as for those particular questions there is only simple comparisons between the teacher and parent samples made so those inferential statistics results are provided in-text.

Participant exposure to education news

A couple of preliminary items were included in our survey to better understand the extent of education news exposure within our samples. Participants generally reported a high exposure to news, with teachers reporting slightly more frequent news consumption $(t(472)=$ $2.34, p=.02, d=0.22$ ). The bulk of participants reported hearing/reading news at least once per day (approx. 84\%), and commonly participants reported hearing/reading news multiple times per day (approx. 57\%), see Figure 1a. News with an education focus appears to be a frequent part of participant experience with news as $67 \%$ of teachers and $44 \%$ of parents estimated that education-focused news comprises at least $10 \%$ of the news items they consume, see Figure 1b. This difference between teacher and parent samples reached statistical significance $(t(472)=3.97, p<.001, d=0.37)$.
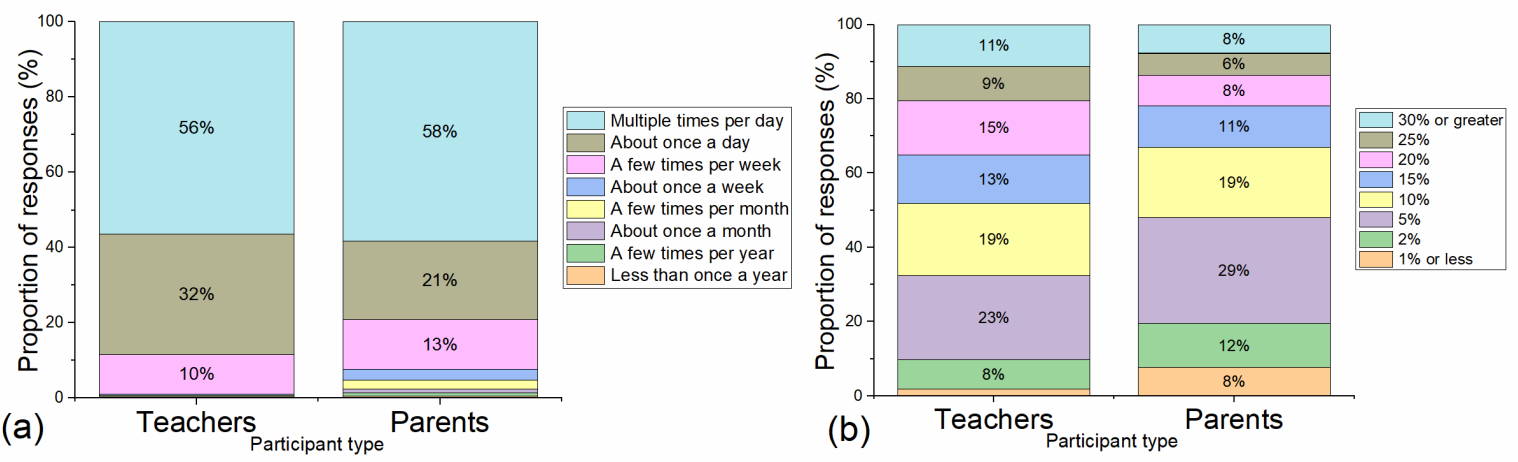

Figure 1. Teacher and parent self-reported responses to questions that assessed (a) the frequency that they listen/read to news, (b) their estimated proportion of the news they consume that has an education focus.

\section{Perceptions of positive/negative tone of educational media coverage}

Participants reported their perception of the general tone of educational media coverage as largely negative, see Figure $2 \mathrm{a} \& \mathrm{~b}$. For teachers, statistically the pattern from most negative 
to least negative is: Teachers $=$ Education system $>$ Schools $>$ NAPLAN, see Figure 1a. Teachers perceive the media coverage of teachers, schools, and the education system as largely negative (approx. 85\%). Many teachers also perceive NAPLAN as receiving generally negative media coverage $(55 \%)$ but this is substantially lower compared to the other rated aspects of education. For parents, the pattern is: Education system $=$ NAPLAN $>$ Schools $>$ Teachers, see Figure 2b. Apart from NAPLAN where parents and teachers did not statistically differ, the parents reported less overall perception of negative media coverage compared to teachers. However, it must still be noted that despite fewer parents perceiving negative media coverage than teachers, the perception of negative media coverage was overall also high for parents across all aspects of education (approx. 64\%). In sum, both teachers and parents mostly perceive media coverage of education as negative, with this more pronounced among teachers.

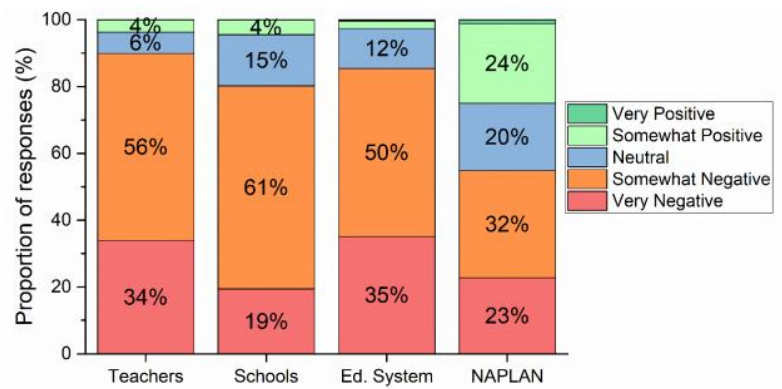

(a) Aspect of education - Teacher ratings

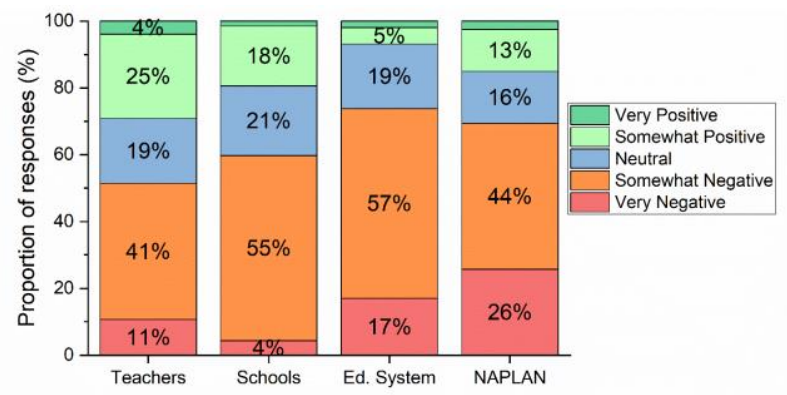

(b) Aspect of education - Parent ratings

Figure 2. The perception of the positive/negative tone of media reports across different aspects of education for (a) teachers, and (b) parents. Please note the labels for percentages less than $3 \%$ are omitted from the charts.

\section{Trust in the media coverage of education}

Both teachers and parents predominately reported low trust in the news media coverage of education, with around $97 \%$ of teachers and $87 \%$ of parents reporting 'a little bit' or 'not at all' trust in media coverage across all aspects of education, see Figure $3 \mathrm{a} \& \mathrm{~b}$. Compared to parents, teachers reported lower trust in media reporting of all aspects of educational media coverage. Across the different aspects, teachers reported the lowest trust in the media reporting about teachers compared with other aspects of education (pattern of mean differences: NAPLAN $=$ Education system $=$ Schools $>$ Teachers), whereas parents reported the lowest trust in NAPLAN media coverage (pattern of mean differences: Teachers $=$ Schools $=$ Education system > NAPLAN). In sum, both teachers and parents generally have little trust in the media coverage of education across all aspects with teachers slightly more distrustful compared to parents.

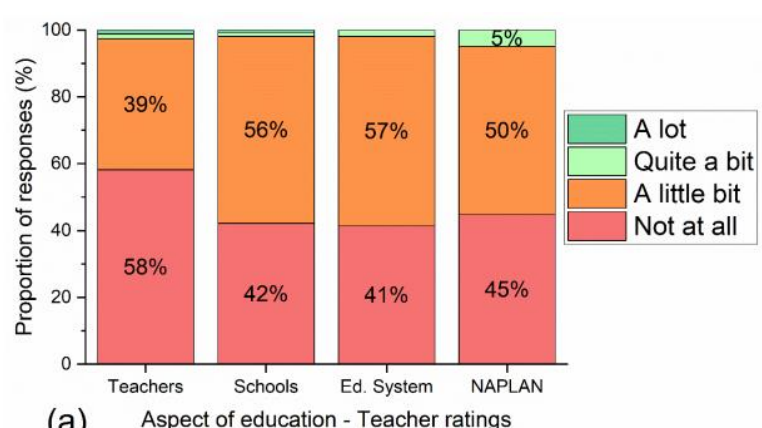

(a) Aspect of education - Teacher ratings

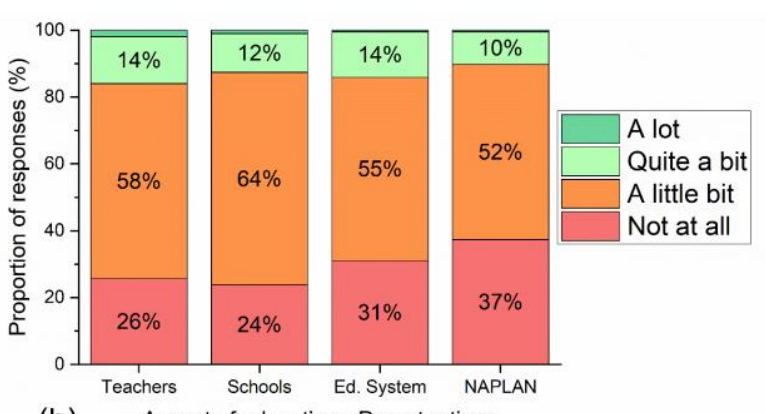

(b) Aspect of education - Parent ratings

Figure 3. The extent of trust in the media reporting of different aspects of education for (a) teachers, and (b) parents. Please note the labels for percentages less than $3 \%$ are omitted from the charts. 


\section{Reactions to positive and negative news media coverage}

Results suggest that negative media stories have potential to have a negative impact on most teachers and parents, see Figure $4 \mathrm{a} \& \mathrm{~b}$. Around $81 \%$ of teachers reported that a negative news story about teachers, schools or the education system demoralises them 'quite a bit' or 'a lot'. This was not the case for NAPLAN where only $26 \%$ of teachers reported a negative NAPLAN story would demoralise them to such an extent. For teachers the pattern among different aspects regarding being demoralised over negative coverage is: Teachers $>$ Schools $>$ Education System > NAPLAN. Compared with teachers the parents reported significantly less extent of demoralisation from negative news stories for all aspects of educational media coverage except for NAPLAN with no significant difference. However, a substantial number of parents (around 50\%) did report being demoralised 'quite a bit' to 'a lot' by negative news stories about teachers, schools, and the education system, see Figure $4 \mathrm{~b}$. Same as the teachers, the parents typically were not as demoralised by negative news stories about NAPLAN compared to the other aspects of education. The pattern of means for parents regarding extent of demoralisation for negative educational news is: Teachers $=$ Schools $=$ Education system $>$ NAPLAN. In sum, a substantial proportion of teachers and parents report feeling demoralised 'quite a bit' or 'a lot' in response to negative news items about teachers, schools and the education system. This is especially so for the teachers. Neither teachers nor parents appear to be as affected by negative news stories about NAPLAN.

While results suggest that negative news can be demoralising, it was also found that positive news can be inspiring. Around $64 \%$ of both teachers and parents reported that when they hear/read about a positive news story about teachers, schools, or the education system they feel inspired 'quite a bit' or ' a lot', see Figure 4c\&d. There is no significant difference between teachers and parents for these aspects, but teachers report being slightly less inspired than parents regarding positive news stories about NAPLAN. However, this difference is small and both teachers and parents report minimal feelings of inspiration from positive NAPLAN news. Indeed, $54 \%$ of teachers and $41 \%$ of parents reported 'not at all' to this question. The pattern of differences across the different aspects was similar for teachers and parents for the questions about inspiration with the pattern for teachers (Teachers > Schools > Education system > NAPLAN), and parents $($ Teachers $=$ Schools $>$ Education system $>$ NAPLAN). In sum, the level of inspiration from positive educational news stories was found to be similar between teachers and parents where members of both groups mostly felt 'quite a bit' or 'a lot' inspired by positive news about teachers, schools, and the education system. Positive news stories about NAPLAN was not associated with much inspiration for either teachers or parents. 

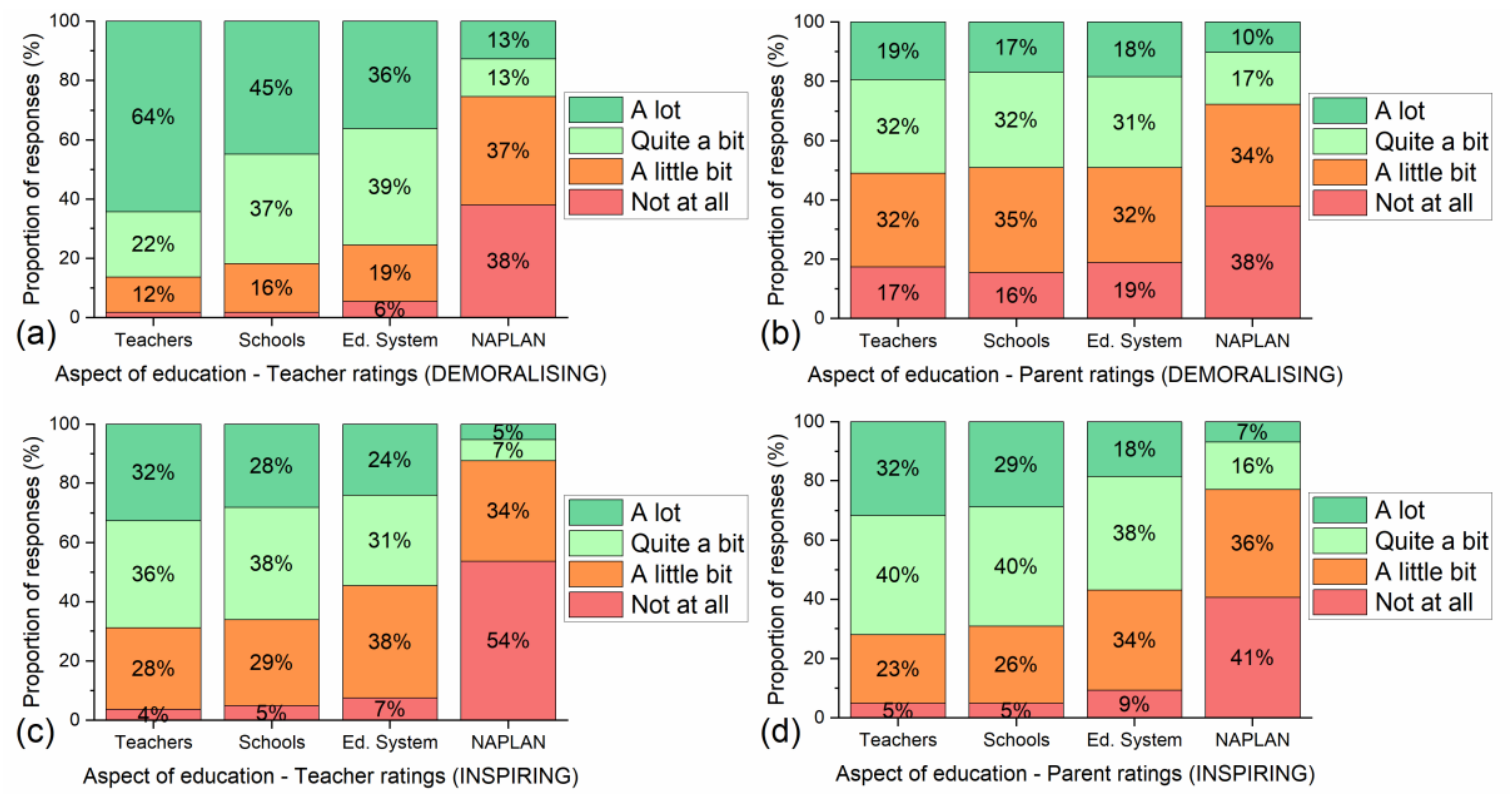

Figure 4. The extent of demoralisation felt upon hearing/reading negative news stories about education for (a) teachers and (b) parents. Also, the extent of inspiration felt upon hearing/reading positive news stories about education for (c) teachers and (d) parents.

\section{The perceived importance of the public perception of education}

Overall, the perceived importance placed upon the public perception of education is high among both teachers and parents, except for NAPLAN which is low, see Figure 5a\&b. The pattern of differences across aspects for teachers is: Teachers > Schools > Education system > NAPLAN. Almost all teachers (around 90\%) responded 'quite a bit' or 'a lot' perceived importance of the public perception of education for teachers, schools, and the education system. A stand-out was the teachers' perception of the importance of the public perception of teachers where $85 \%$ stated 'a lot'. Compared with parents, the teachers generally reported greater importance of the public perception of teachers, schools, and the education system. However, parents did still report generally strong perceived importance of these educational aspects (around $71 \%$ reporting 'quite a bit' or 'a lot'), this was just a bit less than teachers. The pattern of differences across aspects for parents was: Teachers $=$ Schools $=$ Education system $>$ NAPLAN. There was no significant difference regarding the perception of NAPLAN between teachers and parents, and for both groups the perceived importance of the public perception of NAPLAN was low with around $75 \%$ reporting 'not at all' or 'a little bit'. In sum, teachers and parents generally reported feeling that the public perception of teachers, schools, and the education system was quite important to them. They did not typically feel the same way about NAPLAN.

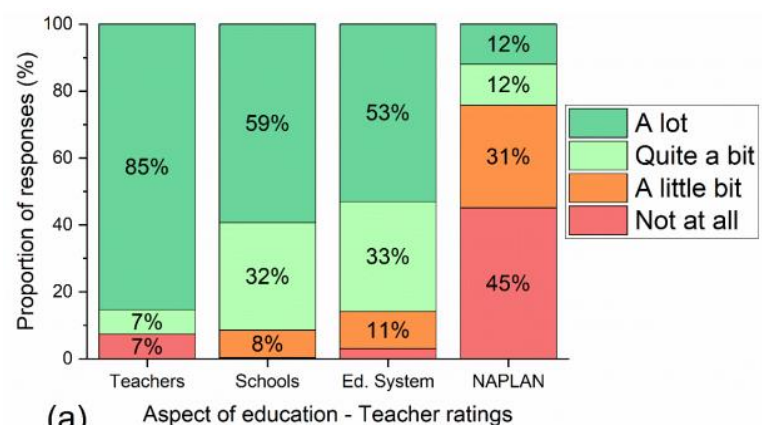

(a) Aspect of education - Teacher ratings

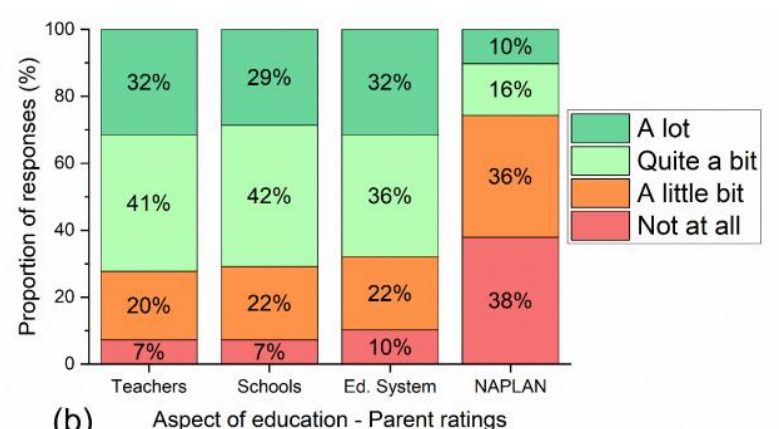

(b) Aspect of education - Parent ratings

Figure 5. The perceived importance of public perception of different aspects of education for (a) teachers and (b) parents. 


\section{Discussion}

It is worth noting from the outset that the group of people surveyed for this study were regular consumers of news. More than 80 per cent engaged with the news at least once a day and more than 50 per cent reported hearing or reading news multiple times a day. The most common estimate by participants regarding what proportion of news consumed had an education focus was about $5-10 \%$. Therefore, the participant perceptions of educational news in our study were based on frequent engagement with news, and educational news in particular, which we argue adds weight to the findings reported here. As per Shine's (2017) previous study, this research found that Australian teachers typically perceive news to be predominately negative. Our extension of Shine's (2017) work was to show that these results extend to a large sample of teachers, and also parents. It could be argued that teachers have a particular sensitivity to news coverage of them and their work environment that may skew their perception. The same argument can't be applied to parents so we argue that this broader view about the negativity of education reporting is significant.

For both teachers and parents, the news coverage relating to the education system was considered an area that received generally negative coverage. As previously discussed, PISA and NAPLAN receive a high degree of media attention relative to other educational issues (Shine 2015). However, such tests are only one measure of large and highly complex educational systems. The news media's preoccupation with testing, standards and performance (Baroutsis \& Lingard 2017; Thomson \& Cook 2014) may be creating an overly negative tone in the reporting, as perceived by teachers and parents. Among teachers interviewed in the Shine (2017) study, a common view was that journalists were only interested in negative news. Yet the teachers generally felt that the public wanted to see more positive stories about schools, students and teachers.

Something that surprised us was the strength of responses from many participants. Pertaining to perceptions of the media reporting of teachers, schools, and the education system most participants felt it to be generally negative (85\% of teachers and $62 \%$ of parents), most had little trust in the reporting (98\% of teachers and $86 \%$ of parents), most felt strongly demoralised by negative education news (81\% of teachers and $50 \%$ of parents) and strongly inspired by positive education news (63\% of teachers and $66 \%$ of parents), and most reported that the public perception of education was quite important to them $(90 \%$ of teachers and $71 \%$ of parents). We argue that the strength of responding highlighted by the present study suggests that news coverage might have a larger emotional impact upon news consumers than what might be intuitively expected.

The participants were generally invested in the issue of news coverage of education. Most teachers and parents cared about how education systems, teachers and schools were portrayed to the public. This finding makes a significant contribution to the literature about news coverage of education, and news more generally, as members of the public have rarely been asked about the importance they place on the way various issues have been represented in the news. In this case, the finding is arguably not surprising for teachers, as it is their chosen profession, and for most would likely form a large part of their identity. However, a similarly strong reaction from parents was not expected. We argue that this high level of personal importance placed upon education can contribute towards explaining the other finding that teachers and parents generally report being emotionally affected by educational news reports.

In terms of the impact of the reporting, a high proportion of teachers (86 per cent) reported being very (i.e., 'quite a bit' or 'a lot') demoralised by negative news stories about teachers. The majority of the teachers interviewed said that negative stories about schools and the education system were also demoralising. In the present study we did not go on to ask if the negative media reporting demoralises teachers to the extent that it reduces job satisfaction 
so we cannot provide any definitive conclusions about that. However, it is reasonable to hypothesize that this might be the case, especially as previous research (MacKenzie 2007; Fetherston \& Lummis, 2012) and surveys (Moore 2019) have found that critical media coverage is a key source of teacher dissatisfaction and cited as a reason why teachers leave the profession. We argue that this is something that warrants further research attention.

The discouraging effect of negative coverage was also seen to a large extent among the parent participants. About half of the parents found negative coverage relating to teachers/schools/ the education system to be demoralising. While it may be expected that coverage of certain events such as war and disaster would have a psychological impact on news consumers, it's surprising to discover that the reporting of a relatively benign topic such as education can also have an emotional impact. This finding reinforces the conclusions of previous research reporting that exposure to negative general news can influence mood and even affect mental health (de Hoog \& Verboon 2020; Baden, McIntyre \& Homberg 2019; Johnston \& Davey 1997; Marin et al. 2012; McNaughton-Cassill 2001; Newman et al. 2019; Szabo \& Hopkinson 2007; Wormwood et al. 2018). On the other hand, we also found that the majority of both teachers and parents typically find positive news stories about teachers, schools, and the education system to be inspiring (i.e., approximately $65 \%$ reported 'quite a bit' or 'a lot'). This is consistent with other studies reporting how positive news can have positive emotional impact on news consumers (Baden, et al. 2019; McIntyre \& Gibson 2016).

As mentioned above, the participant responses across the different educational aspects of teachers, schools, and the education system were overall quite similar. There was however a large contrast between these aspects and NAPLAN. Participants did not place much importance in how the public perceives NAPLAN (around $75 \%$ of teachers and parents responded 'not at all' or 'a little bit'). Considering this it is then not so surprising that compared to the other educational aspects the participants generally did not report much emotional impact from negative or positive media stories about NAPLAN. These results suggest that recent campaigns by teachers and schools to downplay the importance of NAPLAN may be achieving their aims. The annual tests and the release of the tests still make headlines every year in Australia but our research would suggest that news consumers are not particularly interested in, or invested in, such coverage. Nor do they believe it, with $95 \%$ of teachers and $89 \%$ of parents saying they trusted news reports of NAPLAN only a little bit or not at all.

Overall, there was little trust in news reporting for both teachers and parents, consistent with other work which points to a current lack of faith in media in general (Newman, Fletcher, Kalogeropoulos \& Nielsen 2019). Almost all of the teachers (97\%) reported having no trust or only a little bit of trust in news coverage of educational issues. Significantly, parents also reported low levels of trust. Studies such as this confirm that distrust is a genuine and widespread issue for mainstream news outlets, as other surveys and polling have been suggesting.

\section{Conclusion}

In this study we examined public perceptions of news coverage of education, and the emotional effect of this coverage. Our survey participants were teachers $(n=268)$ and 206 parents $(n=206)$ from across Australia, and almost entirely female. Our findings are therefore limited to the Australian (and female) context and future research is required to determine if similar findings exist in other locations and across genders. In our study high proportions of both teachers and parents considered news coverage of educational topics to be negative in tone. Relatively high numbers in both groups also reported being demoralised by negative coverage about teachers, schools and the education system. Additionally, the participants typically reported being inspired by positive stories. Although they did not always trust news coverage, they cared about how education was presented to the public. Teachers may be more 
sensitive to, and critical of, news coverage that relates to their work and their work environment but this study found parents had similar views to teachers about the nature of the coverage. This is significant, we argue, because news organisations are targeting the high number of parents in the community when they cover education news. Education has become a prominent topic of news coverage because editors and journalists have recognised how important educational issues are to parents. Yet this research suggests that parents are dissatisfied with the overly negative tone of the coverage and would welcome a better balance in educational news.

\section{References}

Baden, D., McIntyre, K., \& Homberg, F. (2019). The impact of constructive news on affective and behavioural responses. Journalism Studies, 20(13), 1940-1959. https://doi.org/10.1080/1461670X.2018.1545599

Baroutsis, A. (2016). Media accounts of school performance: reinforcing dominant practices of accountability. Journal of Education Policy, 31(5), 567-582. https://doi.org/10.1080/02680939.2016.1145253

Baroutsis, A., \& Lingard, B. (2017). Counting and comparing school performance: an analysis of media coverage of PISA in Australia, 2000-2014. Journal of Education Policy, 32(4), 432-449. https://doi.org/10.1080/02680939.2016.1252856

Berliner, D., \& Biddle, B. (1995). The Manufactured Crisis: Myths, Fraud, and the Attack on America's Public Schools. Reading, MA: Addison-Wesley

Blackmore, J., \& Thorpe, S. (2003). Media/ting change: The print media's role in mediating education policy in a period of radical reform in Victoria, Australia. Journal of Education Policy, 18(6), 577-595. https://dx.doi.org/10.1080/0268093032000145854

Blackmore, J., \& Thomson, P. (2004). Just 'good and bad news'? Disciplinary imaginaries of head teachers in Australian and English print media. Journal of Education Policy, 19(3), 301-320. https://doi.org/10.1080/0268093042000207638

Coe, K., \& Kuttner, P. J. (2018). Education coverage in TV News: A typology and analysis of 35 years of topics. AERA Open, 4(1), 1-13. https://doi.org/10.1177/2332858417751694

Cohen, J. L. (2010). Teachers in the news: A critical analysis of one US newspaper's discourse on education 2006-2007. Discourse: Studies in the Cultural Politics of Education, 31(1), 105-119. https://dx.doi.org/10.1080/01596300903465450

Culver, K. B., \& Lee, B. (2019). Perceived ethical performance of news media: Regaining public trust and encouraging news participation. Journal of Media Ethics, 34(2), 87101. https://doi.org/10.1080/23736992.2019.1599720

de Hoog, N., \& Verboon, P. (2020). Is the news making us unhappy? The influence of daily news exposure on emotional states. British Journal of Psychology, 111, 157-173. https://doi.org/10.1111/bjop.12389

Doherty, T. J., \& Clayton, S. (2011). The psychological impacts of global climate change. American Psychologist, 66(4), 265-276. https://doi.org/10.1037/a0023141

Fetherston, T., \& Lummis, G. (2012). Why Western Australian secondary teachers resign. Australian Journal of Teacher Education, 37(4), 1-20. https://dx.doi.org/10.14221/ajte.2012v37n4.1

Field, A. (2013). Discovering Statistics using IBM Statistics. London: Sage Publications.

Fink, K. (2019). The biggest challenge facing journalism: A lack of trust. Journalism, 20(1), 40-43. https://doi.org/10.1177/1464884918807069

Goldstein, D. (2015). The Teacher Wars: A History of America's Most Embattled Profession. New York: Anchor Books. 
Hattam, R., Prosser, B., \& Brady, K. (2009). Revolution or backlash? The mediatisation of education policy in Australia. Critical Studies in Education, 50(2), 159-172. https://dx.doi.org/10.1080/17508480902859433

Hargreaves, L., Cunningham, M., Hansen, A., McIntyre, D., Oliver, C., \& Pell, T. (2007). The Status of Teachers and the Teaching Profession in England: Views from Inside and Outside the Profession. Cambridge: University of Cambridge Faculty of Education.

Johnston, W. M., \& Davey, G. C. L. (1997). The psychological impact of negative TV news bulletins: The catastrophizing of personal worries. British Journal of Psychology, 88, 85-91. https://doi.org/j.2044-8295.1997.tb02622.x

Lee, A. M., \& Chyi, H. I. (2013). When Newsworthy is Not Noteworthy. Journalism Studies, 15(6), 807-820. https://doi.org/10.1080/1461670X.2013.841369

Liu, S-H., \& Tsao, S-C. (2013). How did the meanings constructed by Taiwanese pre-service teachers from educational news media affect their beliefs? Educational Media International, 50(2), 135-147. https://doi.org/10.1080/09523987.2013.795353

Lingard, B., \& Rawolle, S. (2004). Mediatizing educational policy: the journalistic field, science policy, and cross-field effects. Journal of Education Policy, 19(3), 361-380. https://doi.org/10.1080/0268093042000207665

MacMillan, K. (2002). Narratives of social disruption: Education news in the British tabloid press. Discourse: Studies in the Cultural Politics of Education, 23(1), 27-38. https://doi.org/10.1080/01596300220123024

Mackenzie, N. (2007). Teacher morale: More complex than we think? The Australian Educational Researcher, 34(1), 89-104. https://doi.org/10.1007/BF03216852

McIntyre, K., \& Gibson, R. (2016). Positive news makes readers feel good: A "silver-lining" approach to negative news can attract audiences. Southern Communication Journal, 81(5), 304-315. https://doi.org/10.1080/1041794X.2016.1171892

McIntyre, K., \& Gyldensted, C. (2018). Positive psychology as a theoretical foundation for constructive journalism. Journalism Practice, 12(6), 662-678. https://doi.org/10.1080/17512786.2018.1472527

McNaughton-Cassill, M. E. (2001). The news media and psychological distress. Anxiety, Stress, and Coping, 14, 193-211. https://doi.org/10.1080/10615800108248354

Mockler, N. (2013). Reporting the 'education revolution': MySchool.edu.au in the print media. Discourse: Studies in the Cultural Politics of Education, 34(1), 1-16. https://doi:10.1080/01596306.2012.698860

Mockler, N. (2015). NAPLAN and the problem frame: Exploring representations of NAPLAN in the print media, 2010 and 2013. In National Testing in Schools (pp. 181-198). Routledge.

Mockler, N. (2018). Discourses of teacher quality in the Australian print media 2014-2017: a corpus-assisted analysis. Discourse: Studies in the Cultural Politics of Education, 1-17. https://doi.org/10.1080/01596306.2018.1553849

Mockler, N. (2019). Shifting the frame: Representations of early career teachers in the Australian print media. In: Sullivan, A., Johnson, B., Simons, M. (eds) Attracting and Keeping the Best Teachers. Professional Learning and Development in Schools and Higher Education, vol 16. Springer, Singapore. https://doi.org/10.1007/978-981-138621-3_4

Moore, T. (2019). One in three Australian teachers leaves in 5 years. Brisbane Times. https://www.brisbanetimes.com.au/national/queensland/one-in-three-australianteachers-leaves-in-first-five-years-inquiry-hears-20190225-p5106h.html

Newman, N., Fletcher, R., Kalogeropoulos, A., \& Nielsen, R. K. (2019). Reuters Institute Digital News Report. http://www.digitalnewsreport.org/ 
Rogers, S. L., Barblett, L., \& Robinson, K. (2016). Investigating the impact of NAPLAN on student, parent and teacher emotional distress in independent schools. The Australian Educational Researcher, 43(3), 327-343.

Rogers, S. L., Barblett, L., \& Robinson, K. (2018). Parent and teacher perceptions of NAPLAN in a sample of Independent schools in Western Australia. The Australian Educational Researcher, 45(4), 493-513.

Rose, J., Low-Choy, S., Singh, P., \& Vasco, D. (2018). NAPLAN discourses: a systematic review after the first decade. Discourse: Studies in the Cultural Politics of Education, 1-16. https://doi.org/10.1080/01596306.2018.1557111

Shine, K. (2015). Are Australian teachers making the grade? A study of news coverage of NAPLAN testing. Media International Australia, 154(February), 25-33. https://doi.org/10.1177/1329878X1515400105

Shine, K. (2017). 'Everything is negative': schoolteachers' perceptions of news coverage of education. Journalism. https://doi.org/10.1177/1464884917743827

Shine, K. (2019). Education Coverage. In T. P. Vos \& F. Hanusch (Eds.), The International Encyclopedia of Journalism Studies. United States: John Wiley \& Sons.

Shine, K., \& O'Donoghue, T. (2013). Schoolteachers in the News. In. New York: Cambria Press.

Snyder, I. (2008). The Literacy Wars. Crows Nest: Allen \& Unwin.

Stack, M. (2006). Testing, testing, read all about it: Canadian press coverage of the PISA results. Canadian Journal of Education / Revue canadienne de l'Ã@ducation, 29(1), 4969.

Szabo, A., \& Hopkinson, K. L. (2007). Negative psychological effects of watching the news in the television: Relaxation or another intervention may be needed to buffer them! International Journal of Behavioral Medicine, 14, 57-62. https://doi.org/10.1007/BF03004169

Thomas, S. (2003). 'The trouble with our schools': A media construction of public discourses on Queensland schools. Discourse: Studies in the Cultural Politics of Education, 24(1), 19-33. https://doi.org/10.1080/01596300303030

Thomas, S. (2006). Education Policy in the Media: Public Discourses on Education. Teneriffe: Post Pressed.

Thomas, S. (2011). Teachers and public engagement: an argument for rethinking teacher professionalism to challenge deficit discourses in the public sphere. Discourse: Studies in the Cultural Politics of Education, 32(3), 371-382. https://dx.doi.org/10.1080/01596306.2011.573253

Thomson, P. (2004). Introduction. Journal of Education Policy, 19(3), 251-252.

Thompson, G., \& Cook, I. (2014). Manipulating the data: Teaching and NAPLAN in the control society. Discourse: Studies in the Cultural Politics of Education, 35(1), 129-142. https://doi.org/10.1080/01596306.2012.739472

Thompson, G., \& Lasic, T. (2011). Doing something about it: Representations of NAPLAN in the public domain. Paper presented at the AARE Annual Conference, Hobart. Retrieved from: https://researchrepository.murdoch.edu.au/id/eprint/9816/

Wallace, M. (1993). Discourse of derision: The role of the mass media within the education policy process. Journal of Education Policy, 8(4), 321-337.

Wallace, M. (2007). Educational myth-making with "due accuracy and impartiality"? A current affairs TV episode in the United Kingdom. Peabody Journal of Education, 82(1), 1031.

Wormwood, J. B., Devlin, M., Lin, Y.-R., Barrett, L. F., \& Quigley, K. S. (2018). When words hurt: affective word use in daily news coverage impacts mental health. Frontiers in Psychology, 9(1333). https://doi:10.3389/fpsyg.2018.01333 
